\title{
STRUCTURAL BEHAVIOUR OF FULLY COUPLED SPAR-MOORING SYSTEM UNDER EXTREME WAVE LOADING
}

\author{
A. B. M. Saiful ISLAMa ${ }^{\mathrm{a}}$ Mohammed JAMEEL ${ }^{\mathrm{a}}$, Suhail AHMAD ${ }^{\mathrm{b}}$, \\ Mohd Zamin JUMAAT ${ }^{\mathrm{a}}$, V. John KURIANc \\ ${ }^{a}$ Department of Civil Engineering, University of Malaya, Kuala Lumpur, Malaysia \\ ${ }^{b}$ Department of Applied Mechanics, Indian Institute of Technology Delhi (IIT Delhi), India \\ ${ }^{c}$ Department of Civil Engineering, Universiti Teknologi PETRONAS, Perak, Malaysia
}

Received 19 Dec 2011; accepted 20 Jan 2012

\begin{abstract}
Floating spar platform has been proven to be an economical and efficient type of offshore oil and gas exploration structure in deep and ultra-deep seas. Associated nonlinearities, coupled action, damping effect and extreme sea environments may modify its structural responses. In this study, fully coupled spar-mooring system is modelled integrating mooring lines with the cylindrical spar hull. Rigid beam element simulates large cylindrical spar hull and catenary mooring lines are configured by hybrid beam elements. Nonlinear finite element analysis is performed under extreme wave loading at severe deep sea. Morison's equation has been used to calculate the wave forces. Spar responses and mooring line tensions have been evaluated. Though the maximum mooring line tensions are larger at severe sea-state, it becomes regular after one hour of wave loading. The response time histories in surge, heave, pitch and the maximum mooring tension gradually decreases even after attaining steady state. It is because of damping due to heavier and longer mooring lines in coupled spar-mooring system under deep water conditions. The relatively lesser values of response time histories in surge, heave, pitch and the maximum mooring tension under extreme wave loading shows the suitability of a spar platform for deep water harsh and uncertain environmental conditions.
\end{abstract}

Keywords: floating structures, spar platform, fully coupled, nonlinear dynamic response, mooring tension, extreme wave loading.

Reference to this paper should be made as follows: Islam, A. B. M. S.; Jameel, M.; Ahmad, S.; Jumaat, M. Z.; Kurian, V. J. 2013. Structural behaviour of fully coupled spar-mooring system under extreme wave loading, Journal of Civil Engineering and Management 19(Supplement 1): S69-S77. http://dx.doi.org/10.3846/13923730.2013.801899

\section{Introduction}

Offshore oil and gas exploration from shallow and intermediate water depths is traditionally carried out using the conventional jacket type fixed platforms. As the water depth increases, fixed platforms becomes uneconomical and the prominence shifts to floating production systems (Hillis, Courtney 2011; Islam et al. 2012a, b). A spar platform is a compliant floating structure used for deep water applications of drilling, production, processing and storage plus off-loading of ocean deposits (Halkyard 1996; Islam et al. 2011a). Numerous studies have recently been performed in order to assess the effect of coupling on different offshore floating production systems/a spar buoy (Chen et al. 2001; Culla, Carcaterra 2007; Ran et al. 1996). Ma and Patel (2001) have conducted parametric studies on Spar and TLP for different depths. Sarkar and Roesset (2004), Grigorenko and Yaremchenko (2009), Kim and Lee (2011), Noorzaei et al. (2010) carried out static as well as dynamic analysis for differ- ent environmental conditions and evaluated the response behaviour. Low and Langley (2007) have compared the methods for the couple analysis of floating structures. Coupled dynamic behaviours of hull/mooring/riser of a spar platform have correspondingly been investigated by several researchers (Chen et al. 2006; Kim et al. 2005, 2001; Islam et al. 2011b). Chen et al. (1999) presented the response of a spar constrained by slack mooring lines to steep ocean waves by two different schemes: a quasi-static approach (SMACOS), and a coupled dynamic approach (COUPLE) to reveal the coupling effects between spar and its mooring system. In coupled dynamic approach, dynamics of a mooring system is calculated using a numerical program, known as CABLE3D.

Ding et al. (2003) presented a numerical code (COUPLE6D) for the coupled dynamic analysis of moored offshore structures. Tahar and Kim (2008) developed a numerical tool for the coupled analysis of a deep water floating platform with polyester mooring lines. Low and

Corresponding author: A. B. M. Saiful Islam

E-mail:abm.saiful@gmail.com 
Langley (2008) presented a hybrid time/frequency domain approach for the coupled analysis of vessel/mooring/riser. The vessel was modelled as a rigid body with six degrees-of-freedom, and the lines were discretized as lumped masses connected by linear extensional and rotational springs. The method was found to be in good agreement with the fully coupled time domain analysis for relatively shallow water depths. Montasir and Kurian (2011) evaluated the effect of slowly varying drift forces on the motion characteristics of truss spar platforms. Yang and Kim (2010) carried out the coupled analysis of a hull-tendon-riser for a TLP. The mooring line/riser/ tendon system was modelled as an elastic rod. It was connected to the hull by linear and rotational springs. The equilibrium equations of hull and mooring line/risers/ tendon system were solved simultaneously. Jameel et al. (2012, 2013) evaluated coupled spar responses considering essential nonlinearities.

Though application of spar platforms is rapidly increasing all over the world, there is a lack of precise modelling and nonlinear coupled response investigation in extreme sea environments. Furthermore, contribution of moorings in terms of drag, inertia and damping for their longer lengths, larger sizes and heavier weights are not fully incorporated, which is more pronounced in deep water conditions. Hence, the main objective of this study is to idealize the spar mooring integrated system as a fully coupled structure; to study the damping effects of mooring lines and to investigate the nonlinear responses under extreme wave loading. Nonlinear coupled responses under the severe sea state have been evaluated in the form of translational motion at surge, heave and rotational motion in pitch direction along with the mooring line tension.

\section{Mathematical model}

The non-linear deterministic model (Fig. 1) for the coupled dynamic analysis includes the formulation of a nonlinear stiffness matrix allowing for mooring line tension fluctuations subjected to variable buoyancy as well as structural and environmental nonlinearities. The model involves selection and solution of wave theory that reasonably represents the water particle kinematics to es-

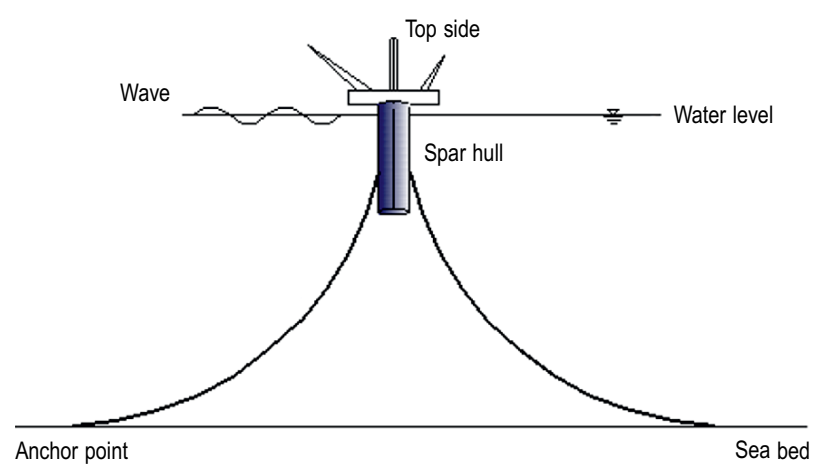

Fig. 1. Sketch of floating spar platform timate the drag and inertia for all of the six degrees of freedom. The static coupled problem is solved by Newton's method. In order to incorporate high degrees of nonlinearities, an iterative time domain numerical integration is required to solve the equation of motion and to obtain the response time histories. The Newmark- $\beta$ time integration scheme with iterative convergence has been adopted for solving the coupled dynamic model. The equation of motion for the spar-mooring system having the equilibrium between inertia, damping, restoring and exciting forces can be accumulated as shown in Eq. (1).

$$
[M]\{\ddot{X}\}+[C]\{\dot{X}\}+[K]\{X\}=\{F(t)\},
$$

where: $\{X\}=6$ DOF structural displacement vector;

$\{\dot{X}\}=$ Structural velocity vector,

$\{\ddot{X}\}=$ Structural acceleration vector;

$[M]=$ Total mass matrix $=[M]^{\text {Spar+Mooring }+}$

$[M]^{\text {Added mass }}$

$[C]=$ Damping Matrix $=[C]^{\text {Structural damping }+}$

$[C]^{\text {Hydrodynamic damping; }}$

$[K]=$ Stiffness matrix $=[K]^{\text {Elastic }}+[K]^{\text {Geometric }}$

The six degrees of freedom (DOF) structural displacements are represented by $\{X\}$ and the dot symbolizes differentiation with respect to time. The total sparmooring mass matrix of the system consists of structural mass and added mass components. The structural mass of the spar-mooring system is made up of elemental consistent mass matrices of the moorings and lumped mass properties of the rigid spar hull. The lumped mass properties are assumed to be concentrated at the CG of a spar hull. The added mass of the structure occurs due to the water surrounding the entire structure. Considering the oscillation of the free surface, this effect of variable submergence is simulated as per Wheeler's approach. The total stiffness matrix element $[K]$ consists of two parts, the elastic stiffness matrix $\left[K_{E}\right]$ and the geometrical stiffness matrix $\left[K_{G}\right]$. The overall damping to the system is contributed by structural and hydrodynamic damping. The major damping is induced due to the hydrodynamic effects. It may be obtained if the structure velocity term in the Morison equation is transferred from the force vector on right hand side to the damping term on the left hand side in the governing equation of motion. The structural damping follows Eq. (2), in which $\xi$ signifies structural damping ratio, $\Phi$ is modal matrix, $\omega_{i}$ denotes natural frequency and $\mathrm{m}_{\mathrm{i}}$ implies the generalized mass.

$$
\Phi^{T}[C]^{\text {Structural }} \Phi=\left[2 \xi \omega_{i} m_{i}\right] .
$$

\subsection{Idealization of mooring line}

The configuration of a mooring line is described by a 3-D Cartesian coordinate system in terms of a vector, $\vec{X}(s, t)$, which is a function of $\mathrm{s}$, the deformed arc length along the mooring line (Fig. 2a). $t, n, b$ are unit vectors in mooring tangential, normal and bi-normal direction respectively at Cartesian coordinate system. The internal 


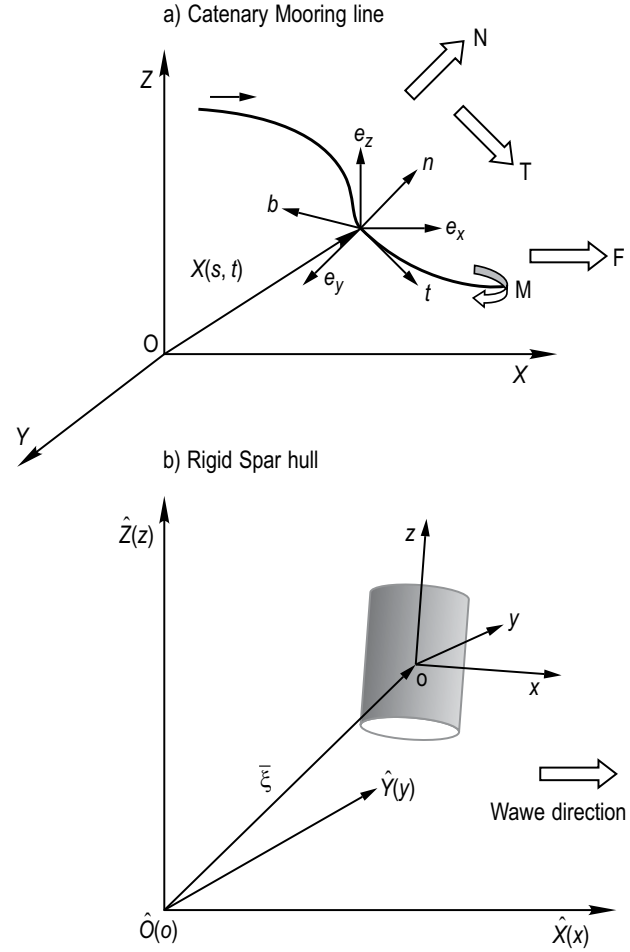

Fig. 2. Coordinate System of mooring line and spar hull

state of stress at a mooring point is described fully by the resultant force and the resultant moment acting at the centreline of the mooring line. The external forces applied on a catenary mooring line involve the gravity forces, hydrostatic forces and hydrodynamic forces. The wave force $F_{m}(X, Z, t)$ per unit length of mooring line acting on a single mooring line can be derived as Eq. (3). Terminologies not mentioned here have been introduced in notations.

$F_{m}(X, Z, t)=F_{\text {Gravity }}+F_{\text {Inertia }}+F_{\text {Drag }}+F^{F-K}$ Sea water.

The aforementioned force can be calculated by:

$F_{m}=\left(\rho_{w} A_{m}-\rho_{i} A_{i}-\rho_{t} A_{t}\right) g e_{z}+$

$\rho_{w} A_{m}\left(I+C_{M n} N+C_{M t} T\right)(\ddot{u}-\ddot{X})+$

$\frac{1}{2} \rho_{w} D C_{D n} N(\dot{u}-\dot{X})|N(\dot{u}-\dot{X})|+$

$\frac{1}{2} \rho_{w} D C_{D t} T(\dot{u}-\dot{X})|T(\dot{u}-\dot{X})|$.

The velocity $\dot{u}$ and acceleration $\ddot{u}$ in Eq. (4) are calculated from an appropriate wave theory. Prime indicates that the derivative is being done with respect to the arc length $\mathrm{s}$ of a mooring line. The subscripts $w, i$ and $t$ denote the sea water, the fluid inside the mooring line and the mooring line tube itself. The term, $I$ is identity matrix. Transfer matrices of tangential forces, $T$ is defined by $T=\mathrm{X}^{\prime T} \mathrm{X}^{\prime}$ and transfer matrices of normal forces, $N=$ $I-T$. As the motion of the structure is considered, there will be addition of some force exerted per unit length acting due to structural acceleration of mooring line element, which is equivalent to $\rho_{\mathrm{w}} A_{m} \ddot{X}$. Adding this term in Eq. (4), the total force acting on a mooring line is given by Eq. (5).

$F_{m}=\left(\rho_{w} A_{m}-\rho_{i} A_{i}-\rho_{t} A_{t}\right) g e_{z}+$

$\rho_{w} A_{m}\left(I+C_{M n} N+C_{M t} T\right) \ddot{u}-\rho_{w}\left(C_{m}-1\right) A_{m} \ddot{X}+$

$\frac{1}{2} \rho_{w} D C_{D n} N(\dot{u}-\dot{X})|N(\dot{u}-\dot{X})|+$

$\frac{1}{2} \rho_{w} D C_{D t} T(\dot{u}-\dot{X})|T(\dot{u}-\dot{X})|$.

The virtual mass matrix is simplified as:

$[M]^{\text {Mooring }}=\left(\rho_{t} A_{t}+\rho_{i} A_{i}\right) I+\rho_{w} A_{m} C_{M n} N+\rho_{w} A_{m} C_{M t} T$.

Hence, the dynamic equilibrium equation of a mooring line can be obtained as Eq. (7).

$$
\begin{aligned}
& {[M]^{\text {Mooring }}\{\ddot{X}\}+\left(\frac{\left[2 \xi \omega_{i m} m_{i m}\right]}{\Phi^{T} \Phi}+\right.} \\
& \left.[C]^{\text {hydrodynamic }}\right)\{\dot{X}\}+\left([K]_{E}^{\text {Mooring }}+\right. \\
& \left.[K]_{G}^{\text {Mooring }}\right)\{X\}=\left(\rho_{w} A_{m}-\rho_{i} A_{i}-\rho_{t} A_{t}\right) g e_{z}+ \\
& \rho_{w} A_{m}\left(I+C_{M n} N+C_{M t} T\right) \ddot{u}-\rho_{w}\left(C_{m}-1\right) A_{m} \ddot{X}+ \\
& \frac{1}{2} \rho_{w} D_{m} C_{D n} N(\dot{u}-\dot{X})|N(\dot{u}-\dot{X})|+ \\
& \frac{1}{2} \rho_{w} D_{m} C_{D t} T(\dot{u}-\dot{X})|T(\dot{u}-\dot{X})|
\end{aligned}
$$

\subsection{Idealization of spar hull}

In the derivation of motion equations of a floating rigid body two coordinate systems have been implemented. Coordinate system $o^{\wedge} x^{\wedge} y^{\wedge} z^{\wedge}$ is a space-fixed coordinate system, while oxyz is the body-fixed coordinate system moving with the body. The origin $o$ can be the centre of gravity $(g)$ or any point fixed on the body. The body-

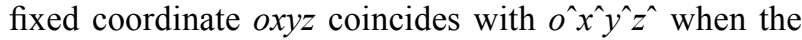
body is at its initial position (Fig. 2b). The third coordinate system $O X Y Z$ which is a spaced-fixed coordinate system with $O X Y$ plan lying on the free surface and $Z$-axis positive upward is also introduced as a reference coordinate system. Incoming waves are applied in this spacefixed reference coordinate system. Therefore, the total force $F_{s}(X, Z, t)$ per unit length on spar hull cylinder can be derived as Eq. (8).

$$
F_{S}(X, Z, t)=F_{\text {Gravity }}+F n_{\text {Inertia }}+F n_{\text {Drag }}+F_{\text {Axial }},
$$

where:

$F_{s}=-\rho_{t} g A_{s} e_{z}+\rho_{w} A_{s} C_{M}\left(\ddot{u}_{n}-\ddot{X}_{n}\right)+$

$\rho_{w} A_{s} C_{M} \ddot{u}_{n}+\frac{1}{2} \rho_{w} D_{s} C_{D}\left(\dot{u}_{n}-\dot{X}_{n}\right)\left|\left(\dot{u}_{n}-\dot{X}_{n}\right)\right|+$

$\rho_{w} \iint_{S_{B}}\left(\frac{\partial\left(\varphi^{(1)}+\varphi^{(2)}\right.}{\partial t}+\frac{1}{2}\left|\nabla \varphi^{(1)}\right|^{2}\right) d s+$

$C_{m t} \rho_{w} \frac{4}{3}\left(\frac{D_{s}}{2}\right)^{3}\left[\ddot{u}_{t}-\ddot{X}_{t}\right]+$

$\frac{1}{2} \rho_{w} C_{D t} A_{s}\left(\dot{u}_{t}-\dot{X}_{t}\right)\left[\left(\dot{u}_{t}-\dot{X}_{t}\right)\right]$. 
Inclusion of the added forces considering motion of structure modifies the total force acting on the spar hull as Eq. (10).

$$
\begin{aligned}
& F_{s}=-\rho_{t} g A_{s} e_{z}+\rho_{w} A_{s} C_{M}\left(\ddot{u}_{n}-\ddot{X}_{n}\right)+ \\
& \rho_{w} A_{s} C_{M} \ddot{u}_{n}+\frac{1}{2} \rho_{w} D_{s} C_{D}\left(\dot{u}_{n}-\dot{X}_{n}\right)\left|\left(\dot{u}_{n}-\dot{X}_{n}\right)\right|+ \\
& \rho_{w} \iint_{S_{B}}\left(\frac{\partial\left(\varphi^{(1)}+\varphi^{(2)}\right.}{\partial t}+\frac{1}{2}\left|\nabla \varphi^{(1)}\right|^{2}\right) d s+ \\
& C_{m t} \rho_{w} \frac{4}{3}\left(\frac{D_{s}}{2}\right)^{3}\left[\ddot{u}_{t}-\ddot{X}_{t}\right]+ \\
& \frac{1}{2} \rho_{w} C_{D t} A_{s}\left(\dot{u}_{t}-\dot{X}_{t}\right)\left[\left(\dot{u}_{t}-\dot{X}_{t}\right)\right]+\rho_{w} A_{s} \ddot{X}_{n} .
\end{aligned}
$$

Therefore, the equation of motion for the spar hull leads to

$$
\begin{aligned}
& {\left[M s+M_{a} s\right]\{\ddot{X}\}+\left(\frac{\left[2 \xi \omega_{i s} m_{i s}\right]}{\Phi^{T} \Phi}+[C]^{\text {hydrodynamic }}\right)\{\dot{X}\}+} \\
& \left([K]_{E}^{\text {Spar }}+[K]_{G}{ }^{\text {Spar }}\right)\{X\}=-\rho_{t} g A_{s} e_{z}+ \\
& \rho_{w} A_{s} C_{M}\left(\ddot{u}_{n}-\ddot{X}_{n}\right)+\rho_{w} A_{s} C_{M} \ddot{u}_{n}+ \\
& \frac{1}{2} \rho_{w} D_{s} C_{D}\left(\dot{u}_{n}-\dot{X}_{n}\right)\left|\left(\dot{u}_{n}-\dot{X}_{n}\right)\right|+ \\
& \rho_{w} \iint_{S_{B}}\left(\frac{\partial\left(\varphi^{(1)}+\varphi^{(2)}\right.}{\partial t}+\frac{1}{2}\left|\nabla \varphi^{(1)}\right|^{2}\right) d s+ \\
& C_{m t} \rho_{w} \frac{4}{3}\left(\frac{D_{s}}{2}\right)^{3}\left[\ddot{u}_{t}-\ddot{X}_{t}\right]+ \\
& \frac{1}{2} \rho_{w} C_{D t} A_{s}\left(\dot{u}_{t}-\dot{X}_{t}\right)\left[\left(\dot{u}_{t}-\dot{X}_{t}\right)\right]+\rho_{w} A_{s} \ddot{X}_{n}
\end{aligned}
$$

\subsection{Equation of motion for a spar-mooring system}

Formation of equation of motion for a spar platform, which combines a spar hull and mooring lines in a single integrated system can be expressed in Eq. (12).

$$
\begin{aligned}
& {\left[M+M_{a}\right]^{\text {Spar+Mooring }}\{\ddot{X}\}+\left(\frac{\left[2 \xi \omega_{i} m_{i}\right]}{\Phi^{T} \Phi}+\right.} \\
& \left.[C]^{\text {hydrodynamic }}\right)\{\dot{X}\}+\left([K]_{E}^{\text {Spar+Mooring }}+\right. \\
& \left.[K]_{G}^{\text {Spar+Mooring }}\right)\{X\}=\left(\rho_{w} A_{m}-\rho_{i} A_{i}-\rho_{t} A_{t}\right) g e_{z}+ \\
& \rho_{w} A_{m}\left(I+C_{M n} N+C_{M t} T\right) \ddot{u}-\rho_{w}\left(C_{m}-1\right) A_{m} \ddot{X}+ \\
& \frac{1}{2} \rho_{w} D_{m} C_{D n} N(\dot{u}-\dot{X})|N(\dot{u}-\dot{X})|+ \\
& \frac{1}{2} \rho_{w} D_{m} C_{D t} T(\dot{u}-\dot{X})|T(\dot{u}-\dot{X})|-\rho_{t} g A_{s} e_{z}+ \\
& \rho_{w} A_{s}\left(\ddot{X}_{n}+C_{M}\left(2 \ddot{u}_{n}-\ddot{X}_{n}\right)\right)+ \\
& \frac{1}{2} \rho_{w} D_{s} C_{D}\left(\dot{u}_{n}-\dot{X}_{n}\right)\left|\left(\dot{u}_{n}-\dot{X}_{n}\right)\right|+ \\
& \rho_{w} \iint_{S_{B}}\left(\frac{\partial\left(\varphi^{(1)}+\varphi^{(2)}\right.}{\partial t}+\frac{1}{2}\left|\nabla \varphi^{(1)}\right|^{2}\right) d s+ \\
& C_{m t} \rho_{w} \frac{4}{3}\left(\frac{D_{s}}{2}\right)^{3}\left[\ddot{u}_{t}-\ddot{X}_{t}\right]+ \\
& \frac{1}{2} \rho_{w} C_{D t} A_{s}\left(\dot{u}_{t}-\dot{X}_{t}\right)\left[\left(\dot{u}_{t}-\dot{X}_{t}\right)\right] .
\end{aligned}
$$

A rigid beam element is considered to model the cylindrical (Rasiulis, Gurkšnys 2010) spar hull connecting its centre of gravity, riser reaction points and mooring lines fair leads. The radii of gyration and the cylinder mass are defined at C.G. The spar platform is associated to the elastic mooring lines by means of six springs (three for translation and three for rotation). The stiffness of translation springs is very high; whereas the stiffness of rotational springs is very low simulating a hinge connection. This model handles all nonlinearities, loading and boundary conditions. The effect of riser in coupling has been ignored. The equation of motion has been solved using the commercial finite element code ABAQUS (2006). It has the capability of modelling slender and rigid bodies with realistic boundary conditions, including fluid inertia and viscous drag (Islam 2013). The mooring lines are modelled as three dimensional tensioned hybrid beam elements. It includes the nonlinearities due to low strain large deformation and fluctuating pretension. It is hybrid because it employs the mixed formulation involving six displacements and axial tension as nodal degrees of freedom. The axial tension maintains the catenary shape of the mooring line. Beam elements experience the wave forces due to Morison's equation. The self-weight and axial tensions are duly incorporated.

Three dimensional stiffness matrixes in ABAQUS are capable of including geometric stiffness matrix with elastic stiffness matrix. $\left[K_{G}\right]$ models the large deformation associated with the mooring configuration. The ABAQUS/ AQUA module appropriately models an off-shore environment. It is capable of simulating the hydrodynamic loading due to a wave. An automatic time interval $(\Delta t)$ incrimination solution scheme representing Newmark- $\beta$ approach is selected. The scheme uses half-step residual control to ensure an accurate dynamic solution. The halfstep residual means the equilibrium residual error (outof-balance forces) halfway through a time increment. For a continuum solution, the equilibrium residual should be moderately small related to significant forces in the problem. This half-step residual check is the basis of the adaptive time interval incrimination scheme. If the halfstep residual is small, the accuracy of the solution is high and the time step can be increased safely; conversely, if the half-step residual is large, the time step taken in the solution ought to be reduced.

\section{Numerical study and discussion of results}

A modelled spar platform has been chosen allowing coupling of a spar-mooring system subjected to ocean waves in $1018 \mathrm{~m}$ deep water. Sea-state having " $\mathrm{W}_{\mathrm{H}}$ " (wave height) and " $\mathrm{W}_{\mathrm{P}}$ " (wave period) of $17.15 \mathrm{~m}$ and $13.26 \mathrm{~s}$ has been considered. The mechanical and geotechnical properties of the spar-mooring system under study are given in Table 1.

Table 2 shows the hydrodynamic characteristics of the marine environment. Mooring tensions are assumed to be equally distributed in all the four mooring lines. The spar hull is expected to behave like a rigid body. When the wave forces act on the entire structure, partic- 
Table 1. Mechanical and Geometrical Properties of Spar-mooring system

\begin{tabular}{|c|c|c|}
\hline \multirow[t]{2}{*}{ Element } & \multicolumn{2}{|c|}{ Properties } \\
\hline & Length & $213.044 \mathrm{~m}$ \\
\hline \multirow{7}{*}{$\begin{array}{l}\text { Spar } \\
\text { (Classic } \\
\text { JIP Spar) }\end{array}$} & Diameter & $40.54 \mathrm{~m}$ \\
\hline & Draft & $198.12 \mathrm{~m}$ \\
\hline & Mass & $2.515 \mathrm{E} 8 \mathrm{~kg}$ \\
\hline & Mooring Point & $106.62 \mathrm{~m}$ \\
\hline & No. of Nodes & 17 \\
\hline & No. of Elements & 16 \\
\hline & Type of Element & Rigid beam element \\
\hline \multirow{2}{*}{ Sea water } & Depth & $1018 \mathrm{~m}$ \\
\hline & Density & $1026 \mathrm{~kg} / \mathrm{m}^{3}$ \\
\hline \multirow{7}{*}{$\begin{array}{l}\text { Mooring } \\
\text { line }\end{array}$} & No. of Moorings & 4 \\
\hline & Stiffness (EA) & $1.501 \mathrm{E}+09 \mathrm{~N}$ \\
\hline & Length & $2000 \mathrm{~m}$ \\
\hline & Mass & $1100 \mathrm{~kg} / \mathrm{m}$ \\
\hline & Mooring line pre-tension & $1.625 \mathrm{E}+07 \mathrm{~N}$ \\
\hline & No. of Nodes & 101 \\
\hline & Element Type & Hybrid beam elemen \\
\hline
\end{tabular}

Table 2. Hydrodynamic properties

\begin{tabular}{lll}
\hline Structural element & \multicolumn{1}{c}{ Hydrodynamic coefficient } \\
\hline \multirow{4}{*}{ Spar } & Drag coefficient & 0.6 \\
& Inertia coefficient & 2.0 \\
& Added mass coefficient & 1.0 \\
& Drag coefficient in vertical direction & 3.0 \\
Mooring line & Drag coefficient & 1.0 \\
& Inertia coefficient & 2.2 \\
& Added mass coefficient & 1.2 \\
\hline
\end{tabular}

ipation of mooring lines in the overall response is well depicted. The variable boundary conditions due to mooring anchor point are appropriately incorporated. Due to the ideal modelling, the solution is having difficulty in convergence. Responses of spar and mooring lines under extreme regular wave have been evaluated.

The coupled form of structural modelling predicts true behaviour of spar-mooring system. This approach yields dynamic equilibrium between the forces acting on the spar and the mooring line at every time station. The computational efforts required for the coupled analysis including all mooring lines are substantial. The ability for more accurate prediction of platform motions by coupled analysis approach may consequently contribute to a smaller and comparatively less expensive spar-mooring system and hence a lighter spar platform through a lessening in payload requirements. The excursion time histories are found for sufficient length of time so that the response attains their steady state. To understand the mooring damping and coupling effect, long range responses are obtained. The responses in terms of surge, heave, pitch and mooring line tension are plotted for $17.15 \mathrm{~m} 13.26 \mathrm{~s}$ wave loading. The sea state has been
Table 3. Severe dynamic stresses (Jameel, Ahmad 2011)

\begin{tabular}{ccccc}
\hline Sea State & $\mathrm{W}_{\mathrm{H}}(\mathrm{m})$ & $\mathrm{W}_{\mathrm{P}}(\mathrm{sec})$ & $\begin{array}{c}\mathrm{RMS} \text { stress } \\
(\mathrm{MPa})\end{array}$ & $\begin{array}{c}\text { Probability } \\
\text { of occurrence }\end{array}$ \\
\hline $\mathrm{S} 1$ & 17.15 & 13.26 & 123.81 & 0.0000003 \\
\hline $\mathrm{S} 2$ & 15.65 & 12.66 & 122.74 & 0.0000023 \\
\hline $\mathrm{S} 3$ & 14.15 & 12.04 & 122.34 & 0.0000143 \\
\hline $\mathrm{S} 4$ & 12.65 & 11.39 & 121.88 & 0.0000798 \\
\hline $\mathrm{S} 5$ & 11.15 & 10.69 & 121.38 & 0.0004057 \\
\hline $\mathrm{S} 6$ & 9.65 & 9.94 & 120.09 & 0.0018712 \\
\hline $\mathrm{S} 7$ & 8.15 & 9.14 & 119.67 & 0.0077382 \\
\hline $\mathrm{S} 8$ & 6.65 & 8.26 & 118.98 & 0.0282212 \\
\hline $\mathrm{S} 9$ & 5.15 & 7.26 & 117.89 & 0.0885110 \\
\hline $\mathrm{S} 10$ & 3.65 & 6.12 & 117.46 & 0.2283116 \\
\hline $\mathrm{S} 11$ & 2.15 & 4.69 & 116.82 & 0.4354235 \\
\hline $\mathrm{S} 12$ & 0.65 & 2.58 & 115.93 & 0.2094203 \\
\hline
\end{tabular}

defined as critical by Jameel and Ahmad (2011). Among all the sea states of their study (Table 3), sea state S1 (17.15 m wave height and $13.26 \mathrm{~s}$ wave period) is large in loading magnitude but lowest in probability of occurrence. Therefore, in this study, the sea state $\mathrm{S} 1$ has been selected for the assessment of the structural behaviour under extreme wave loading.

\subsection{Validation of present coupled spar-mooring system model}

The validation of the present model has been done with experimental study in OTRC wave basin, Texas A \& M University conducted by Chen et al. (2001) with good agreement. Chen et al. (2001) have stated the difference of the maximum net tension in four mooring lines at the fair lead position, changing against various static off-sets in surge direction. The responses are obtained under regular wave loading of $\mathrm{W}_{\mathrm{H}}=6 \mathrm{~m} ; \mathrm{W}_{\mathrm{P}}$ and $14 \mathrm{~s}$ in $1018 \mathrm{~m}$ deep water condition. Fig. 3 shows the identical mooring line tension response variation with the Spar off-set at range $0 \sim 10 \mathrm{~m}$ for the same deep water sea state. The illustration shows a bit difference with Chen et al. (2001) for all the off-sets ranging after $10 \mathrm{~m}$ to $25 \mathrm{~m}$. However, the trend of the results is rather matching. The variation in the numerical values of net tension is mainly due to the basic difference in mathematical model. The present

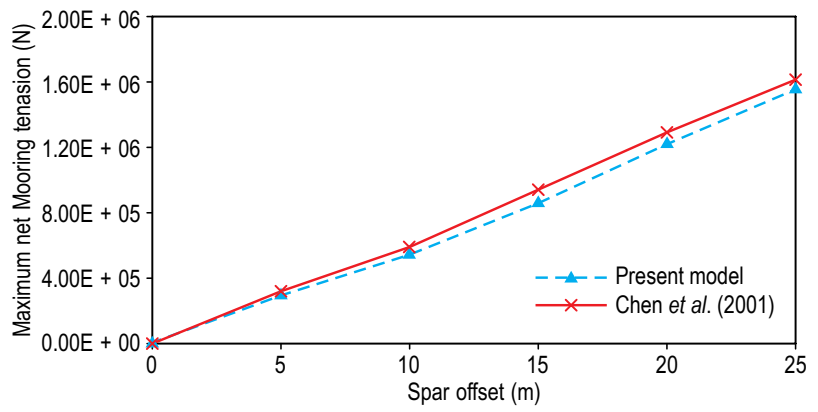

Fig. 3. Assessment of present model output with experimental result 
study takes into account, the actual integrated coupling of entire structure by finite element assembly considering all major nonlinearities, while Chen et al. (2001) did it differently. The identical values attained in the present study confirm the validity of the fully coupled integrated model. Furthermore, it indicates that for the required state of equilibrium, the boundary conditions are appropriately implemented.

The comparison of natural time periods between Chen et al. (2001) and the present study has been carried out as well. Free vibration analysis of a spar platform is performed. Lanczos method has been used to obtain the natural frequencies and corresponding mode shapes. The natural periods obtained by Chen et al. (2001) are 331.86, 29.03 and 66.77 seconds in surge, heave and pitch respectively at $318 \mathrm{~m}$ water depth, which is very close with the present model result at the same depth with corresponding values of $323.97,25.60$ and 59.48 seconds. Furthermore, in $1018 \mathrm{~m}$ water depth, the natural periods obtained by the present simulation are 341.97 , 22.60 and 43.48 in surge, heave in pitch direction. In comparison to the experimentally measured values (Chen et al. 2001), the present model values are expected. Due to the increase of water depth, surge time period increases but heave and pitch time periods decrease. These satisfactory assessments in consistent manner prove the accuracy of the present model.

\subsection{Spar responses}

\subsubsection{Surge at platform level}

The time series of surge response due to the sea state $\mathrm{S} 1$ at the deck level and CG level of the spar platform are shown in Figs 4 and 5, respectively. The peak of the surge response at deck level for the sea state $\mathrm{S} 1$ ranges from $+22.50 \mathrm{~m}$ to $-14.11 \mathrm{~m}$. The nature of the surge at the deck level is predominantly periodic as shown in Fig. 4. Pitch motion (Fig. 6) occurs simultaneously with surge and attracts significant wave energy close to the pitch frequency. Surge response requires huge energy input because of large inertia and hence does not get excited. However, pitching motion occurring with surge gets excited easily. The surge response at the deck level is dominated by the pitching motion of the hull with insignificant excitation of surge mode. It is mainly due to the coupling of surge and pitch. Effect of non-linearity is not very strong on the surge response.

\subsubsection{Surge at the spar centre of gravity}

The translational response in surge direction at the centre of gravity of a spar is shown in Fig. 5 for 1018 m water depth. It shows a marked difference in surge behaviour in comparison to the same at platform level (Fig. 4). At CG level, it oscillates in similar regular pattern as the platform level responses. However, the fluctuations of the surge are small in value compared to the deck level excursions. There are continuous fluctuations of wave frequency, showing the pronounced non-linear behaviour. The mean value of surge shows a lateral shift of a spar by $4.25 \mathrm{~m}$.

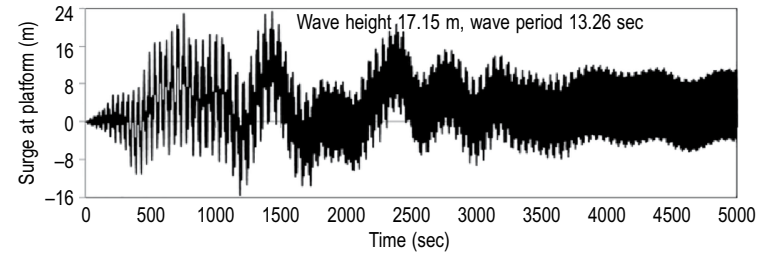

Fig. 4. Spar translational motion response in surge direction at deck level

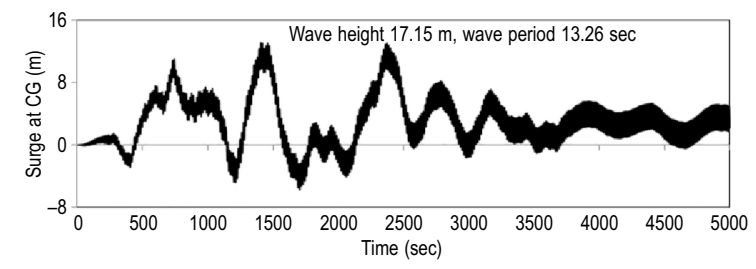

Fig. 5. Spar translational motion response in surge direction at $\mathrm{CG}$

The surge response at deck level attains steady state at around $4000 \mathrm{sec}$. However, the response at CG level shows that the whole system needs more time to damp out the initial transient effect.

\subsubsection{Spar response in heave direction}

The heave response directly influences the mooring tensions and other operations. The heave response under regular wave for sea state S1 is shown in Fig. 6. The time history shows the cluster of reversals occurring at varying time intervals. The phenomenon displays regularity in the response behaviour. Larger magnitudes of heave responses occur earlier for the S1 wave loading. The maximum heave response of $1.6 \mathrm{~m}$ occurs around $1300 \mathrm{sec}$. The steady state is attained approximately at $3500 \mathrm{~s}$ of wave loading. The heave response fluctuates about the mean position oscillating from smaller to larger amplitudes and repeating the same trend onwards all through the time history for both cases. The fluctuations gradually increase from narrow to broad by $20 \%$. Reaching the peak, it gradually reduces by $10 \%$ and again increases ensuring the similar trend.

Though the heave response attains steady state around $2400 \mathrm{sec}$, its value of oscillations gradually decreases till $4500 \mathrm{sec}$. This shows the damping of heave response due to longer and heavier mooring lines in deep water conditions. The relatively low value of heave for extreme wave loading also indicates the suitability of a spar platform for harsh deep water environment.

\subsubsection{Spar response in pitch direction}

The pitch behaviour of a spar hull subjected to regular sea waves is illustrated in Fig. 7. The time history of pitch response shows regular fluctuations initiating from zero up to peak of $\pm 0.10 \mathrm{rad}$. The pitch responses reduce periodically and again increase through taking energy. For the sea state S1, the steady state is observed within 1 hour. The significant value of pitch response leads to 


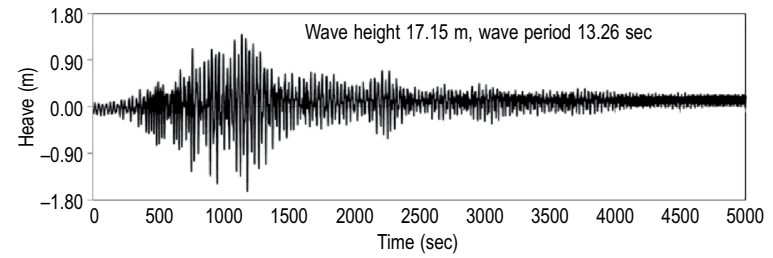

Fig. 6. Spar translational motion response in heave direction

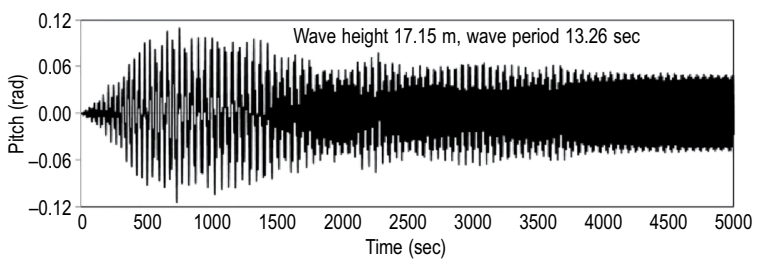

Fig. 7. Spar rotational motion response in pitch direction

a significant surge at the deck level. It is coupled with the surge of rigid hull, which otherwise is of small magnitude but gets enhanced due to the pitch input. This is why the surge time history shows the maximum peak at pitch frequency. The pitch time history also shows similar behaviour as surge time history.

\subsubsection{Maximum tension response in mooring lines}

The response of mooring lines plays an important role in the coupled dynamic analysis of the spar platform. The regular wave loads simultaneously act on the hull and mooring lines. The analysis of this structure yields the coupled response in the true sense. Designed pretension in each mooring line of the present problem is $1.625 \mathrm{E}+07 \mathrm{~N}$ (Table 1). A mooring line shows the regular behaviour of tension when subjected to the sea state S1 (Fig. 8). The surge response also causes increase in tension. The mooring line 1 is positioned in the direction of wave propagation before the spar hull. It is worth mentioning that the mooring line 1 experiences the maximum tension to support surge in the forward direction. Figs 8-9 show the tension fluctuations when the mooring line 1 and the mooring line 3 stretch respectively due to surge response. The tension fluctuation is of complex periodic nature showing minor ripples near the peaks. For both of these mooring lines at the regular wave periodic behaviour is governed.

The maximum tension time history in the mooring line 3 is shown in Fig. 9. As mentioned earlier, the mooring line 1 is in the direction of wave. It stretches due to wave action causing the mooring line 3 to slack. This phenomenon of stretch and slack repeats alternatively. Both of the mooring lines attain steady state approximately after $3500 \mathrm{sec}$, the fluctuations of pretension ranges from $1.50 \mathrm{E}+07 \mathrm{~N}$ in the mooring line 3 . The oscillation pattern for both mooring lines is identical. Compared to the mooring line 1 , the mean value of tension fluctuations for the mooring line 3 is relatively less. This behaviour is expected because the mooring line 3 slacks due to extreme wave loading.

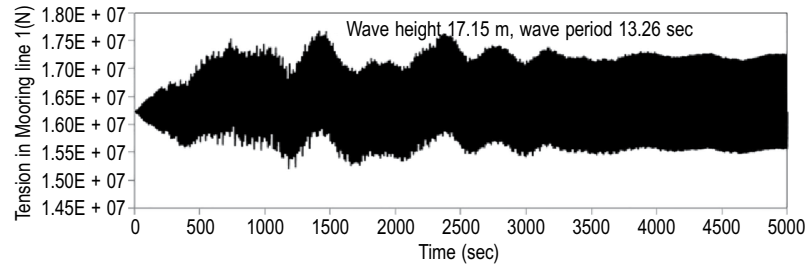

Fig. 8. Maximum tension in mooring line 1

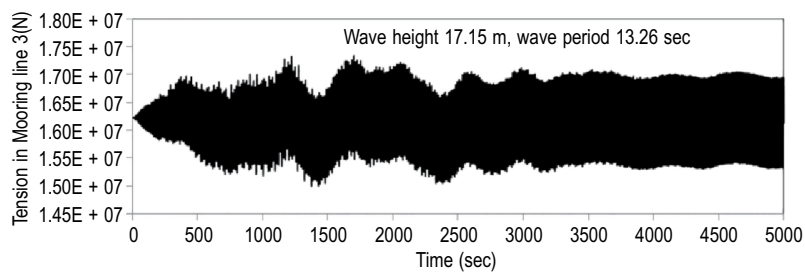

Fig. 9. Maximum tension in mooring line 3

\section{Summary and conclusions}

For deep water offshore exploration, spar platforms have been recognized as efficient and economical structures. The finite element model for coupled analysis of spar and its mooring system developed in this study is capable of handling all nonlinearities, loading and boundary conditions. The conclusions of this study are as follows:

1) The spar response gets significantly modified and mean position of oscillations gets shifted for the extreme wave loading. For extreme regular wave, of $\mathrm{W}_{\mathrm{H}}=17.15 \mathrm{~m}, \mathrm{~W}_{\mathrm{P}}=13.26 \mathrm{sec}$ at $1018 \mathrm{~m}$ water depth, the surge, heave and pitch responses are predominantly excited.

2) The fluctuations of surge at the spar CG are small in value compare to the deck level excursions. The mean value of the surge at $C G$ shows a lateral shift of the spar by $4.25 \mathrm{~m}$.

3) The response time histories in surge, heave, pitch and the maximum mooring tension gradually decreases even after attaining the steady state. It is because of damping due to heavier and longer mooring lines in the coupled spar-mooring system under deep water conditions.

4) The relatively lesser values of response time histories in surge, heave, pitch and the maximum mooring tension under extreme wave loading shows the suitability of spar platform for deep water harsh and uncertain environmental conditions.

\section{Acknowledgement}

The authors gratefully acknowledge the University of Malaya (UM), for supporting this work through grants RG093-10AET and PV052-2011B.

\section{Notations}

$A_{i}=$ Inner cross-sectional area of the mooring line; $A_{m}=$ Outer cross-sectional area of the mooring line; $A_{s}=$ Cross-sectional area of the spar hull; $A_{t}=$ Structural cross-sectional area of the mooring line; 
$C_{D}=$ Drag coefficient;

$C_{M}=$ Inertia coefficient;

$C_{m t}=$ Added-mass coefficient of the Spar cylinder bottom;

$C_{D t}=$ Drag coefficient of the Spar cylinder bottom;

$D_{m}=$ Diameter of mooring line;

$D_{s}=$ Diameter of the spar hull;

$e_{X}=$ Unit vector in X-axis;

$e_{y}=$ Unit vector in Y-axis;

$e_{z}=$ Unit vector in Z-axis;

$P_{w}=$ Pressure of the sea water;

$P_{i}=$ Pressure of the internal fluid;

$\varphi^{(1)}=$ First-order potential of incident waves;

$\varphi^{(2)}=$ Second-order potential of incident waves;

$\rho_{w}=$ Mass density of the sea water;

$\rho_{m}=$ Mass per unit mooring line;

$\rho_{s}=$ Mass density of the spar.

\section{References}

ABAQUS. 2006. ABAQUS documentation version 6.9.1: Karlson \& Sorensen, Inc.

Chen, X.; Ding, Y.; Zhang, J.; Liagre, P.; Niedzwecki, J.; Teigen, P. 2006. Coupled dynamic analysis of a mini TLP: Comparison with measurements, Ocean Engineering 33(1): 93-117. http://dx.doi.org/10.1016/j.oceaneng.2005.02.013

Chen, X.; Zhang, J.; Ma, W. 2001. On dynamic coupling effects between a spar and its mooring lines, Ocean Engineering 28(7): 863-887. http://dx.doi.org/10.1016/S0029-8018(00)00026-3

Chen, X.; Zhang, J.; Ma, W. 1999. Coupled time-domain analysis of the response of a spar and its mooring system, in International Offshore Polar Engineering Conference (ISOPE), 1999, 293-300.

Culla, A.; Carcaterra, A. 2007. Statistical moments predictions for a moored floating body oscillating in random waves, Journal of Sound and Vibration 308(1-2): 44-66. http://dx.doi.org/10.1016/j.jsv.2007.07.018

Ding, Y.; Kim, M.; Chen, X.; Zhang, J. 2003. A numerical code (COUPLE6D) for coupled dynamic analysis of moored offshore structures, in Proceedings of International Symposium on Deepwater Mooring Systems 2003. Houston, Texas, USA. ASCE, 168-182.

Grigorenko, A.; Yaremchenko, S. 2009. Investigation of static and dynamic behavior of anisotropic inhomogeneous shallow shells by Spline approximation method, Journal of Civil Engineering and Management 15(1): 87-93. http://dx.doi.org/10.3846/1392-3730.2009.15.87-93

Halkyard, J. E. 1996. Status of Spar platforms for deepwater production systems, in Proceedings of the Sixth International Offshore and Polar Engineering Conference, May 26-31, 1996. Los Angels, California, USA. International Society of Offshore and Polar Engineers, 262-272.

Hillis, A. J.; Courtney, C. R. P. 2011. Structural health monitoring of fixed offshore structures using the bicoherence function of ambient vibration measurements, Journal of Sound and Vibration 330(6): 1141-1152. http://dx.doi.org/10.1016/j.jsv.2010.09.019

Islam, A. B. M. S.; Jameel, M.; Jumaat, M. Z. 2011a. Effect of time elapse after wave hitting on coupled Spar platform, International Journal of the Physical Sciences 6(11): 2671-2680.

Islam, A. B. M. S.; Jameel, M.; Jumaat, M. Z.; Shirazi, S. M. 2011b. Spar platform at deep water region in Malaysian sea, International Journal of the Physical Sciences 6(30): 6872-6881.
Islam, A. B. M. S.; Jameel, M.; Jumaat, M. Z. 2012a. Oil and gas energy potential at Malaysian sea bed and Spar platform for deep water installation, International Journal of Green Energy 9(2): 111-120. http://dx.doi.org/10.1080/15435075.2011.621493

Islam, A. B. M. S.; Jameel, M.; Jumaat, M. Z.; Shirazi, S. M.; Salman, F. A. 2012b. Review of offshore energy in Malaysia and floating Spar platform for sustainable exploration, Renewable and Sustainable Energy Reviews 16(8): 6268-6284. http://dx.doi.org/10.1016/j.rser.2012.07.012

Islam, A. B. M. S. 2013. Nonlinear dynamic behaviour of fully coupled Spar platform: Ph D thesis, University of Malaya, Kuala Lumpur, Malaysia.

Jameel, M.; Ahmad, S. 2011. Fatigue Reliability Assessment of Coupled Spar-Mooring System, in ASME, ed. ASME 30 $0^{\text {th }}$ International Conference on Ocean, Offshore and Arctic Engineering, (OMAE 2011-49687), 19-24 June 2011. Rotterdam, The Netherlands.

Jameel, M.; Islam, A. B. M. S.; Khaleel, M.; Jumaat, M. Z. 2012. Nonlinear finite element analysis of spar platform, Advanced Science Letters 13: 723-726. http://dx.doi.org/10.1166/asl.2012.3851

Jameel, M.; Ahmad, S.; Islam, A. B. M. S.; Jumaat, M. Z. 2013. Nonlinear dynamic analysis of coupled spar platform, Journal of Civil Engineering and Management 19(4): 476-491.

Kim, M. H.; Koo, B. J.; Mercier, R. M.; Ward, E. G. 2005. Vessel/mooring/riser coupled dynamic analysis of a turretmoored FPSO compared with OTRC experiment, Ocean Engineering 32(14-15): 1780-1802.

http://dx.doi.org/10.1016/j.oceaneng.2004.12.013

Kim, M.; Lee, J. H. 2011. Study on nonlinear pavement responses of low volume roadways subject to multiple wheel loads, Journal of Civil Engineering and Management 17(1): 45-54.

http://dx.doi.org/10.3846/13923730.2011.554012

Kim., M. H.; Ward, E. G.; Harnig, R. 2001. Comparison of numerical models for the capability of hull/mooring/ riser coupled dynamic analysis for Spars and TLPs in deep and ultra deep water, in Proceedings of the Eleventh International Offshore and Polar Engineering Conference, 2001. International Society of Offshore and Polar Engineers, 474-479.

Low, Y. M.; Langley, R. S. 2007. A comparison of methods for the couple analysis of floating structures, in Proceedings of the $26^{\text {th }}$ International Conference on Offshore Mechanics and Arctic Engineering (OMAE), 2007. San Diego, USA. ASME.

Low, Y. M.; Langley, R. S. 2008. A hybrid time/frequency domain approach for efficient coupled analysis of vessel/ mooring/riser dynamics, Ocean Engineering 35(5-6): 433-446. http://dx.doi.org/10.1016/j.oceaneng.2008.01.001

Ma, Q. W.; Patel, M. H. 2001. On the non-linear forces acting on a floating spar platform in ocean waves, Applied Ocean Research 23(1): 29-40. http://dx.doi.org/10.1016/S0141-1187(00)00025-0

Montasir, O. A.; Kurian, V. J. 2011. Effect of slowly varying drift forces on the motion characteristics of truss spar platforms, Ocean Engineering 38(13): 1417-1429. http://dx.doi.org/10.1016/j.oceaneng.2011.07.007

Noorzaei, J.; Abdulrazeg, A. A.; Jaafar, M. S.; Kohnehpooshi, O. 2010. Nonlinear analysis of an integral bridge, Journal of Civil Engineering and Management 16(3): 387-394. http://dx.doi.org/10.3846/jcem.2010.44

Ran, Z.; Kim, M. H.; Niedzwecki, J. M.; Johnson, R. P. 1996. Response of a Spar platform in random waves and currents (experiment vs. theory), International Journal of Offshore and Polar Engineering 6(1): 27-34. 
Rasiulis, K.; Gurkšnys, K. 2010. Analyses of the stress intensity of the cylindrical tank wall at the place of the geometrical defect, Journal of Civil Engineering and Management 16(2): 209-215. http://dx.doi.org/10.3846/jcem.2010.23

Sarkar, I.; Roesset, J. M. 2004. Variability of results of dynamic analysis of Spars, in Proceedings of the fourteenth International Offshore and Polar Engineering Conference, 2004. May 23-28, Toulon, France. International Society of Offshore and Polar Engineers, 650-654.
Tahar, A.; Kim, M. H. 2008. Coupled-dynamic analysis of floating structures with polyester mooring lines, Ocean Engineering 35(17-18): 1676-1685. http://dx.doi.org/10.1016/j.oceaneng.2008.09.004

Yang, C. K.; Kim, M. H. 2010. Transient effects of tendon disconnection of a TLP by hull-tendon-riser coupled dynamic analysis, Ocean Engineering 37(8-9): 667-677. http://dx.doi.org/10.1016/j.oceaneng.2010.01.005

A. B. M. Saiful ISLAM obtained his PhD from the Department of Civil Engineering, University of Malaya, Malaysia. He has completed his BSc in Civil Engineering and MSc in Structural Engineering from Bangladesh university of Engineering and Technology (BUET), Bangladesh. He works as a Research Fellow at University of Malaya. He is a member of Institution of Engineers, Bangladesh and American Society of Civil Engineers (ASCE). His research interests include Offshore structures, Nonlinear dynamics, Finite element modelling, Seismic protection, Base isolation, Pounding and Special tall buildings.

Mohammed JAMEEL did his PhD at Indian Institute of Technology Delhi (IIT Delhi), India. He has successfully completed various sponsored projects involving nonlinear analysis of TLPs, Spar, FPSO platforms, deep and shallow water mooring lines and Risers. The projects were supported by several government and private funding agencies. Presently he is associated with Department of Civil Engineering, University of Malaya, Malaysia. His research area includes Non-linear Dynamics, Earthquake engineering, Reliability engineering, Offshore structures, Artificial neural network and Nonlinear finite element analysis.

Suhail AHMAD works at the Department of Applied Mechanics, IIT Delhi, India. He earned his academic qualifications from UCS Swansea, UK, IIT Delhi, University of Roorkee, AMU Aligarh, India. He has guided $15 \mathrm{PhD}$ theses. He has more than 100 research papers to his credit. He has made distinguished professional contributions. His research interest includes Computational mechanics, Off-Shore structures, Dynamics, Reliability Engineering, Composites and FEM.

Mohd Zamin JUMAAT is a Professor and a Head of the Department of Civil Engineering, University of Malaya, Malaysia. He is a member of Institution of Engineers, Malaysia and a member of the Drafting Code Committee for reinforced concrete structures. His research interests include behaviour of offshore structures, reinforced concrete structural elements, concrete materials, selfconsolidating concrete, lightweight concrete and green concrete.

V. John KURIAN is a Professor of Civil Engineering in the Faculty of Engineering at the PETRONAS University of Technology, Malaysia. He is a member of ISOPE, Concrete Society of Malaysia, Institution of Engineers (India) and Indian Society for Technical Education. His research interests include the analysis and design of offshore structures, especially the floaters. 